\title{
Triboelectricity Generation from Vertically Aligned Carbon Nanotube Arrays
}

\author{
Moses Oguntoye, Michael Johnson ${ }^{\ddagger}$ Lawrence Pratt and Noshir Pesika ${ }^{*}$
}

Department of Chemical and Biomolecular Engineering, Tulane University, 6823 St. Charles Avenue, New Orleans, Louisiana 70118, United States

₹ Department of Chemistry, Tulane University, 6823 St. Charles Avenue, New Orleans, Louisiana 70118, United States *Corresponding author. Tel: 614 316-2744. Email: npesika@tulane.edu (Noshir Pesika) 


\section{Experimental Materials and Methods}

VACNT electrodes were fabricated directly on stainless steel (SS) foil current collectors via water-assisted $\mathrm{CVD}^{16}$. The SS foils were first cleaned and then coated with successive layers of $50 \mathrm{~nm}$ molybdenum, $20 \mathrm{~nm}$ aluminum and $1.5 \mathrm{~nm}$ iron using e-beam evaporation (Angstrom Engineering). The foils were placed in a 4 in. quartz tube furnace (MTI Corporation) where a $15 \% \mathrm{H}_{2}$ in Ar gas mixture flows as the temperature was ramped up to $775^{\circ} \mathrm{C}$. At $775^{\circ} \mathrm{C}$, ethylene and water vapor were introduced into the furnace and this was maintained for a total growth time of $90 \mathrm{~min}$ to yield $1 \mathrm{~mm}$ thick VACNT carpets. The furnace was cooled back to room temperature in an Ar gas atmosphere. The PTFE electrode was made by sputtering a $50 \mathrm{~nm}$ thick gold layer (as current collector) onto one side of a thin PTFE sheet and the PET electrode was used as purchased with ITO (current collector) coated on one side. Electrical connections to the electrodes' current collectors were made using double-sided adhesive copper tape. The TENG was assembled by stacking both electrodes, separated by two layers of 0.031 in double-sided foam tape acting as a spacer, on a glass slide.

The morphology of the prepared VACNT was examined using scanning electron microscopy (Hitachi 4800 SEM) and transmission electron microscopy (FEI Tecnai G2 F30 Twin). Repeated contact was made using a programmable CETR tribometer programmed to exert a $400 \mathrm{~g}$ (or $4 \mathrm{~N}$ ) mechanical load in all experiments. The distance between the two TENG electrodes remains fixed (except during contact) due to the adhesive nature of the spacers. Voltage and current measurements were made using a RIGOL oscilloscope and a PAR263A potentiostat respectively. A $0.47 \mu \mathrm{F}$ capacitor was charged by connecting it to the PTFE-VACNT TENG via a bridge rectifier. 


\begin{tabular}{|c|c|c|c|c|c|c|}
\hline Reference & Electrode Materials & $\begin{array}{l}\text { Contact Area } \\
(\mathrm{cm} 2)\end{array}$ & $\begin{array}{l}\text { Contact } \\
\text { Frequency } \\
\text { (Hz) } \\
\text { (approx.) }\end{array}$ & Load & $\begin{array}{l}\text { Max. Open- } \\
\quad \text { circuit } \\
\text { voltage (V) }\end{array}$ & $\begin{array}{l}\text { Max. Short- } \\
\text { circuit } \\
\text { current }(\mu \mathrm{A})\end{array}$ \\
\hline $\begin{array}{l}\text { S. Lee, Y. Lee, D. Kim, Y. Yang, L. Lin, Z.H. Lin, et al., Triboelectric } \\
\text { nanogenerator for harvesting pendulum oscillation energy, Nano Energy. } 2 \\
\text { (2013) 1113-1120. doi:10.1016/j.nanoen.2013.08.007. }\end{array}$ & PDMS-Aluminum & 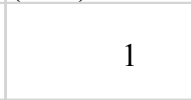 & 0.9 & - & 3.8 & 0.5 \\
\hline $\begin{array}{l}\text { B. Saravanakumar, K. Thiyagarajan, N.R. Alluri, S. SoYoon, K. } \\
\text { Taehyun, Z.H. Lin, et al., Fabrication of an eco-friendly composite } \\
\text { nanogenerator for self-powered photosensor applications, Carbon } 84 \\
\text { (2015) 56-65. doi:10.1016/j.carbon.2014.11.041. }\end{array}$ & $\begin{array}{l}\mathrm{PDMS} / \mathrm{ZnO} / \mathrm{rGO}- \\
\text { Aluminum }\end{array}$ & 16 & 0.85 & $\begin{array}{l}\text { Foot } \\
\text { stamp }\end{array}$ & 8 & 0.8 \\
\hline $\begin{array}{l}\text { F.R. Fan, Z.Q. Tian, Z. Lin Wang, Flexible triboelectric generator, Nano } \\
\text { Energy. } 1 \text { (2012) 328-334. doi:10.1016/j.nanoen.2012.01.004. }\end{array}$ & Kapton-PET & 5.4 & 0.33 & - & 3.2 & 0.22 \\
\hline $\begin{array}{l}\text { Y. Mao, D. Geng, E. Liang, X. Wang, Single-electrode triboelectric } \\
\text { nanogenerator for scavenging friction energy from rolling tires, Nano } \\
\text { Energy. } 15 \text { (2015) 227-234. doi:10.1016/j.nanoen.2015.04.026. }\end{array}$ & PDMS & 1 & 3 & $5 \mathrm{~N}$ & 2.5 & 2.5 \\
\hline $\begin{array}{l}\text { F.R. Fan, Z.Q. Tian, Z. Lin Wang, Flexible triboelectric generator, Nano } \\
\text { Energy. } 1 \text { (2012) 328-334. doi:10.1016/j.nanoen.2012.01.004. }\end{array}$ & PET-PVC & 5.4 & 0.33 & - & 3.2 & 0.15 \\
\hline This work & VACNT-PET & 1 & 0.14 & $4 \mathbf{N}$ & 1.42 & 0.16 \\
\hline This work & VACNT-PTFE & 1 & 0.14 & $4 N$ & 3.2 & 0.21 \\
\hline $\begin{array}{l}\text { X. Cheng, Y. Song, et al. A flexible large-area triboelectric generator by } \\
\text { low-cost roll-to-roll process for location-based monitoring, Sensors and } \\
\text { Actuators A. } 247 \text { (2016) 206-214 }\end{array}$ & PVC-PET & 150 & 1 & 375 & 400 & 30 \\
\hline $\begin{array}{l}\text { T. Li, Y. Su, et al. Lightweight triboelectric nanogenerator for energy } \\
\text { harvesting and sensing tiny mechanical motion, Advanced Funtional } \\
\text { Materials. } 26 \text { (2016) 4370-4376 }\end{array}$ & Nylon - PVDF & 11.25 & 1.33 & $\begin{array}{l}\text { Finger } \\
\text { tapping }\end{array}$ & 75 & 6 \\
\hline
\end{tabular}

Table S1. Comparison of current and voltage output in this work with current and voltage output of other unstacked TENG assemblies.

Comparing the performance of TENGs is often hindered by the use of different working conditions in testing the output of TENGs. In the table above, we have outlined how our VACNT TENGS perform compared to other TENGs based on maxima of the open-circuit voltage and short-circuit current. Also included, where possible, are the three major variables that affect the TENG output: contact area, contact frequency and load. TENG output increases with an increase in each of these three variables. As shown in the table, VACNT array electrodes have the potential to perform comparably or better than some of the other electrodes listed since they show comparable performance with lower force, significantly lower frequency and in some cases, lower area. 
Video S1. Demonstration of generation of triboelectricity from PTFE-VACNT TENG using manual contact. 


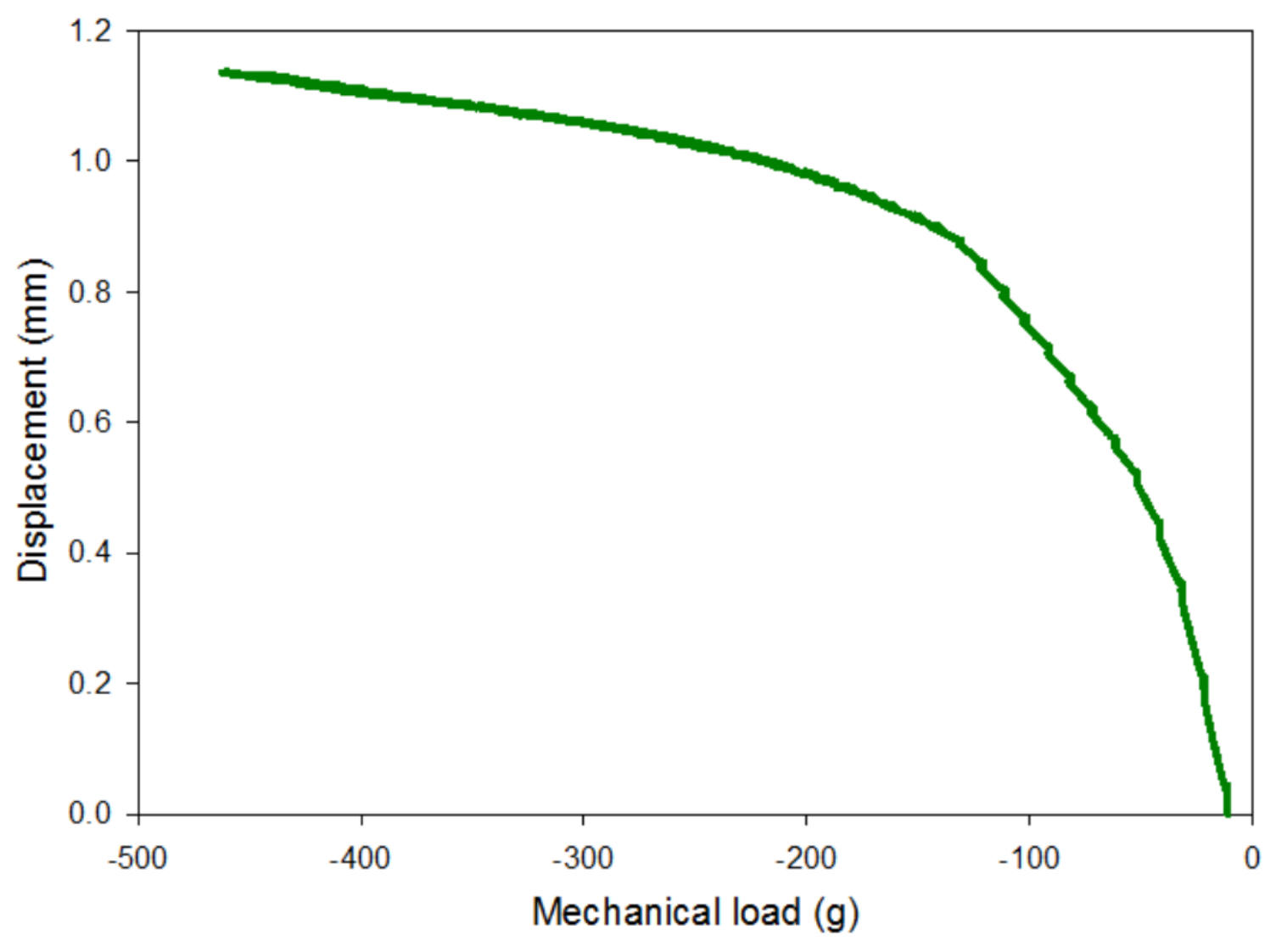

Figure S1: Mechanical load capability of the VACNT-PTFE TENG. Contact area $\approx 1 \mathrm{~cm}^{2}$.

The spacing between the two electrodes is $\approx 0.9 \mathrm{~mm}$ and so contact is made at about $150 \mathrm{~g}$ mechanical load. The further displacement is as a result of the bending of the tips of the VACNT arrays that produces a higher surface area of contact between the two electrodes thereby leading to higher current and voltage output. 


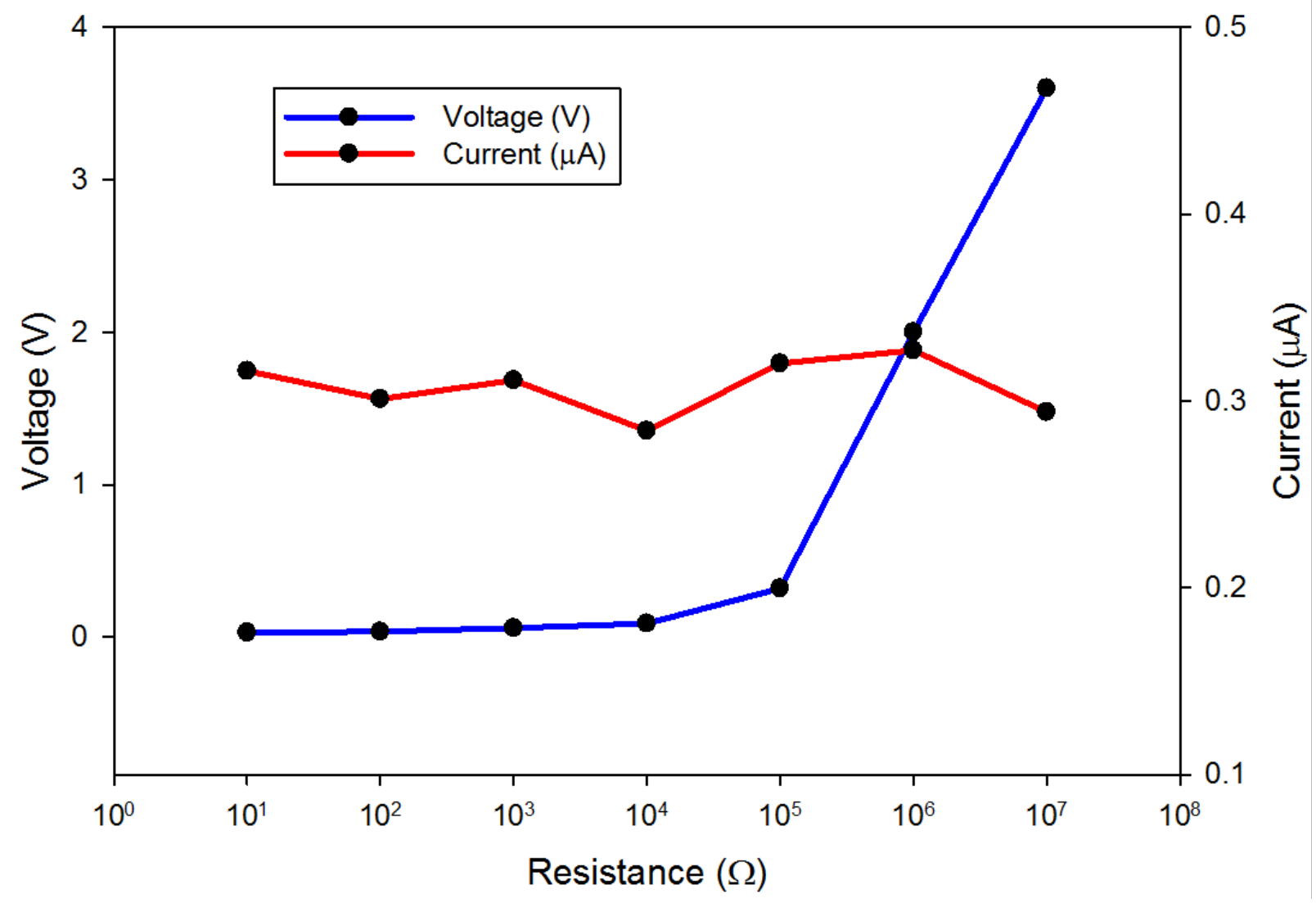

Figure S2: Electrical load capability of the VACNT-PTFE TENG. Contact area $\approx 1 \mathrm{~cm}^{2}$, Contact force $=4 \mathrm{~N}$. Frequncy $=0.14 \mathrm{~Hz}$.

The electrical load graph above shows that in the VACNT-PTFE TENG, the current remains constant across the entire range of $10 \Omega$ to $10 \mathrm{M} \Omega$ resistors tested. This means that the VACNT-PTFE TENG is capable of providing instantaneous power for a wide range of electrical loads albeit at different amplitudes. The voltage rises at higher loads as is customary in the TENG however the peak voltage may be obtainable at a resistive load that exceeds the range tested in this study. For the range of resistors tested, the best performance is obtained at $10 \mathrm{M} \Omega$ with a maximum instantaneous power of $1.06 \mu \mathrm{W}$. 


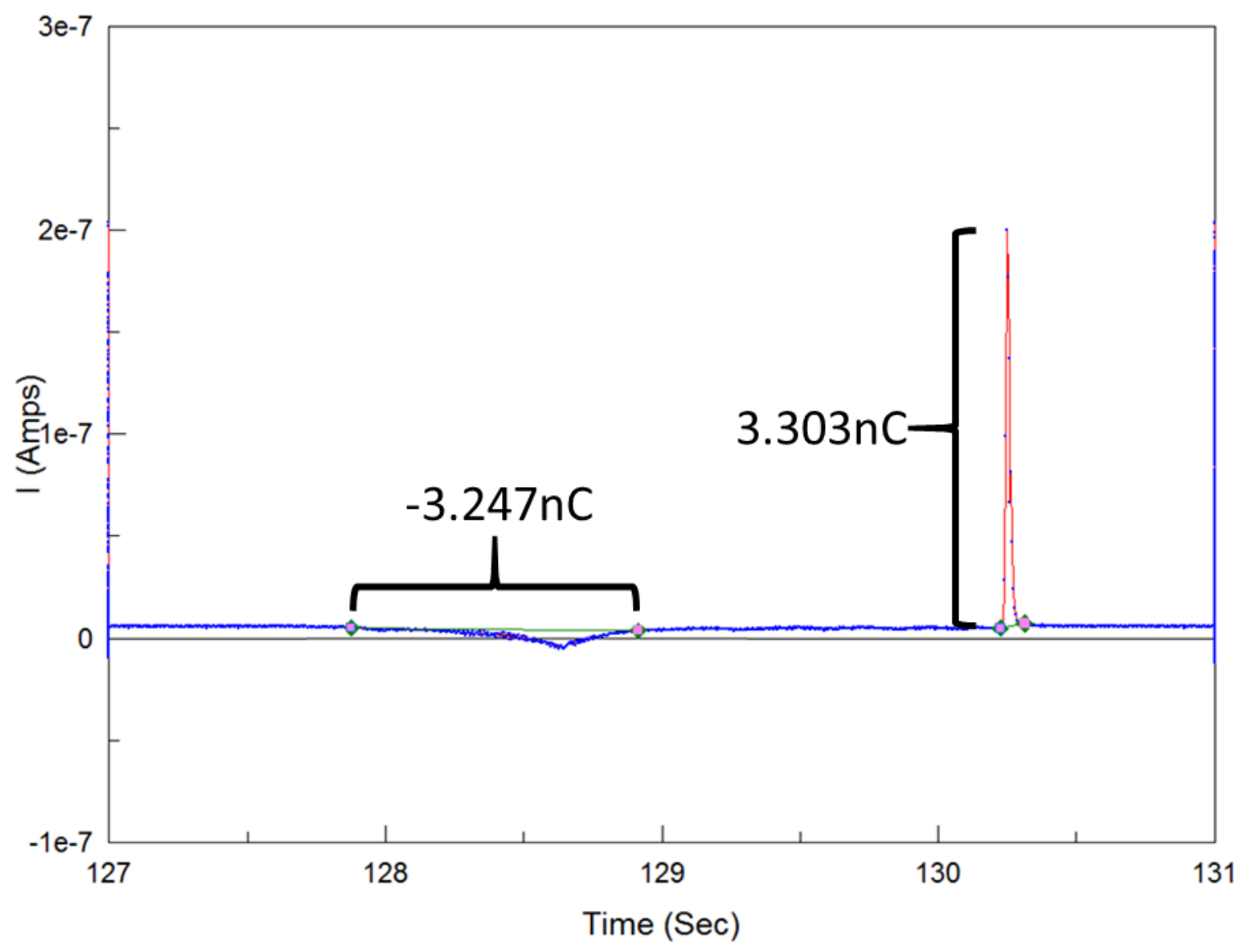

Figure S3. Charge transferred during one contact cycle. Charge transfer figures are obtained by integrating the current peaks.

The figure above and values obtained show that despite the differences in peak heights, the charge transferred is effectively equal during contact and separation of the TENG. Also, this figure shows that the instantaneous power obtainable with the TENG can be increased by increasing the speed of contact or separation since these lead to higher current peaks. 

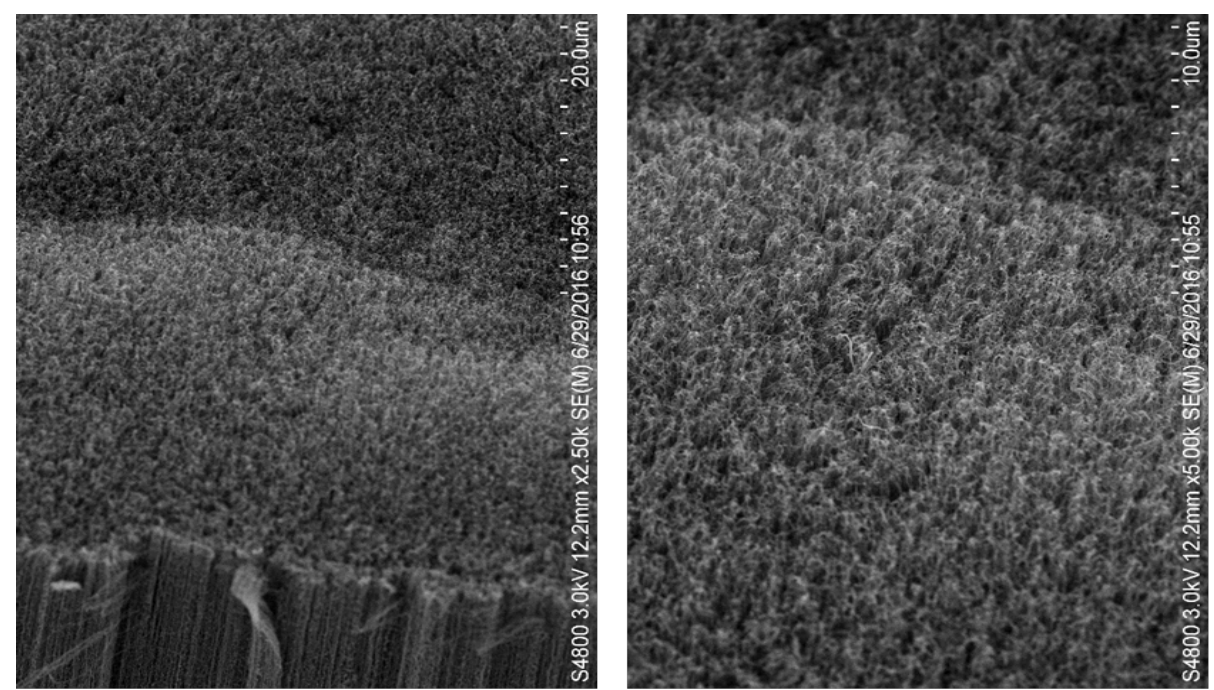

\section{Before 20k compression cycles}
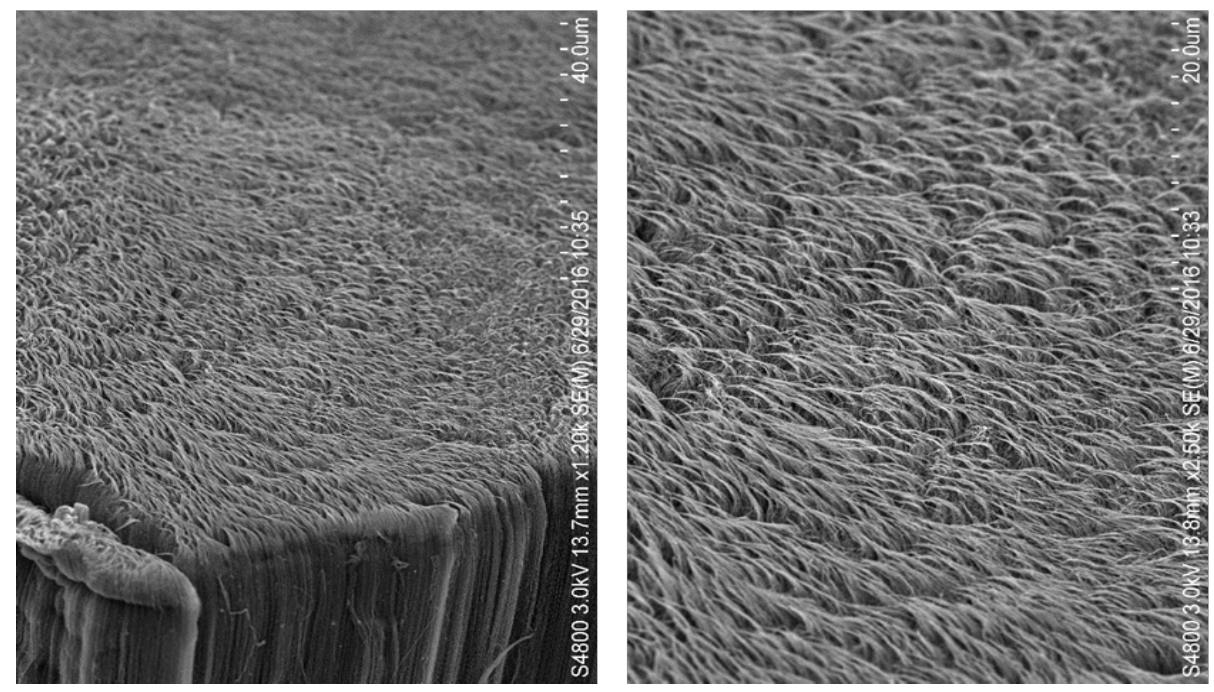

\section{After $20 \mathrm{k}$} compression cycles

Figure S4. SEM micrographs showing bending at the tips after the VACNT-PTFE TENG has been contacted over 20000 times $\left(\right.$ contact area $\approx 3.0 \mathrm{~cm}^{2}$; contact force $=4 \mathrm{~N}$ ). Besides what is seen in the images, no other structural effect was observed on the VACNT array after contact. 

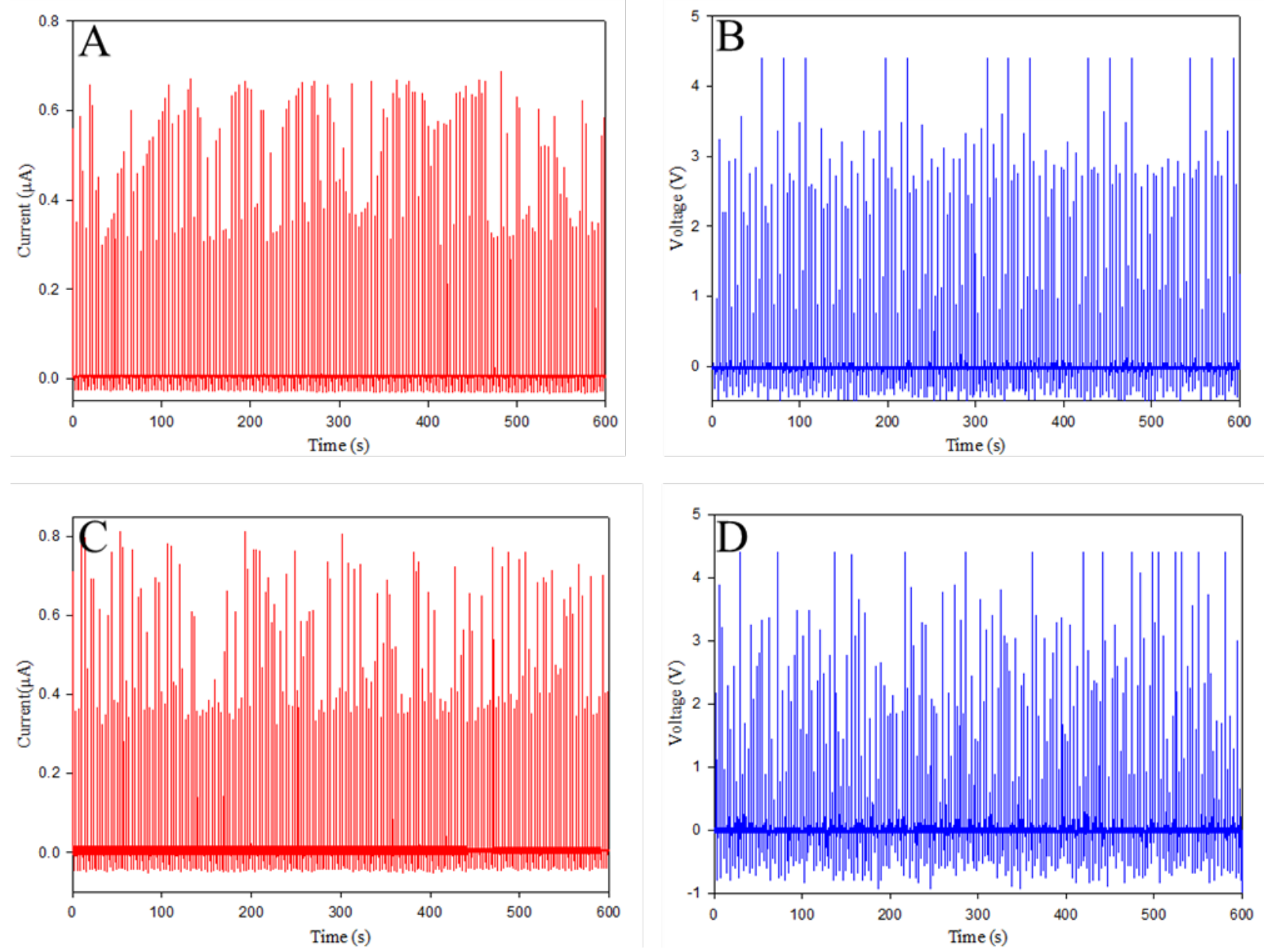

Figure S5. A Current and B. Voltage measurements for VACNT-PTFE TENG for the first 10 minutes of 20k cycles; C. Current and D. Voltage measurements for the VACNT-PTFE TENG for the last 10 minutes of 20k cycles. $\left(\right.$ contact area $\approx 3.0 \mathrm{~cm}^{2} ;$ contact force $\left.=4 \mathrm{~N}\right)$. 